\title{
A realidade do mundão: uma narrativa sobre a sociedade e a produção da desigualdade
}

Mariana Medina Martinez

(UFSCAR)

\section{INTRODUÇÃO}

Este artigo analisa a dimensão política de uma narrativa crítica sobre a sociedade e a produção da desigualdade 1 . O estudo parte de uma pesquisa de campo ${ }^{2}$ realizada com "moradores de rua" da cidade de São Carlos/SP. Devo dizer que as aspas são necessárias para demarcar o uso de uma categoria política reivindicada pelas pessoas que vivem nas ruas e apreendida em campo durante a realização de uma oficina que coordenei em uma instituição de assistência social com atendimento voltado para a população de rua. A homogeneidade sugerida no termo não exprime, de modo algum, a multiplicidade das trajetórias de rua, cuja característica descontínua e fragmentária, discutida em trabalhos anteriores (Martinez 2011), revela uma dimensão política outra $^{3}$. Entretanto, para fazer valer a apreciação crítica do relato, foram omitidas as variações das trajetórias de rua em favor de uma categoria uniforme capaz de operacionalizar uma narrativa por meio da qual o "morador de rua" enuncia e constrói uma visão de mundo.

$O$ argumento contido neste discurso diz respeito à produção da verdade sobre as relações sociais por meio das experiências vividas nas ruas. A verdade, para os "moradores de rua", é extraída do conflito, porque ele é o ponto central de articulação das relações. $\mathrm{O}$ acesso à verdade só é possível para aqueles que vivem ou conhecem a realidade - o mundo concreto constituído por diversos tipos de embates. A versão falsa do real é enganosa uma vez que envolve necessariamente a dissimulação a respeito das relações humanas. Do ponto de vista de quem vive nas ruas, a ameaça e o perigo permanentes em suas vidas revelam um mundo de relações hostis, o qual chamam de mundão. Esta visão peculiar da sociedade diferencia-se das demais porque é apreendida por aqueles que experimentam a violência em seu cotidiano. Apresentarei a descrição etnográfica de realidade e sociedade, dois conceitos que muito embora pareçam ser convencionais no pensamento ocidental, na conjuntura 
das ruas ganham uma implicação original. $O$ terceiro conceito apresentado - diferente dos demais porque aparece com uma entonação própria - diz respeito à descrição do mundo em que os "moradores de rua" dizem viver; é o mundão. $\mathrm{O}$ enunciado pretende esboçar um caminho de reflexão que contribua para a necessária problematização das dinâmicas sociais de exclusão em que tais atores estão inscritos.

Meu interesse é mostrar como são percebidas no cotidiano e elaboradas discursivamente as formações e tensões sociais que marcam o universo das relações de desigualdade, no qual os "moradores de rua" detêm a posição mais desprivilegiada. Trazer à tona este conjunto de discursos expressos em verbos ou em atos se presta a anunciar em texto o que (possivelmente) pensam os "moradores de rua" a respeito do funcionamento social. Mais do que isso, elucidar os seus modos de pensar (e de agir) nos ajuda a refletir sobre os processos de marginalização com as ferramentas conceituais deles próprios e não com as nossas - nós que, para eles, não conhecemos a realidade.

Ao manifestar um discurso incomum, busco deslocar a ação política da dimensão institucional - ali onde a política é naturalizada no Estado ou nos partidos - para modular novas formas de expressão política. Em outras palavras, busco trazer para o centro da discussão um discurso considerado desqualificado por ser julgado insuficientemente elaborado e não conceitual, que nos dizeres de Deleuze e Guattari (1995) são saberes menores ${ }^{4}$, ou ainda, nas palavras de Foucault (2005 [1976]), são saberes sujeitados ${ }^{5}$.

O desafio deste artigo é levar a sério um discurso marginalizado que, por sua condição, é potente em indicar alguns dos muitos conflitos presentes na dinâmica urbana. A tarefa implica em percorrer o sentido oposto do caminho seguido pelo debate público atual, apostando numa abordagem positiva das chamadas periferias. Ou seja, a tentativa é apostar em um tratamento analítico no qual os chamados marginalizados não sejam apenas matéria de expressão da pobreza, como há muito os estudos da área vêm interpretando a condição do marginal - pelo menos desde a década de 1970 no Brasil. Desde esta época, alguns autores dedicaram-se a avaliar formas de integração social da população pobre (Durham 1973; Kowarick 1979; Santos 1979). Ou ainda, muito da discussão sobre as periferias fomentou questões sobre os movimentos sociais em São Paulo, buscando nos territórios da pobreza o modelo mais radical de desarticulação política (Durham 1973; Caldeira 1984). Assim, os pobres quase sempre foram estudados do ponto de vista normativo, sendo definidos no sentido da falta, carência e desajuste ao corpo social.

Entretanto, ao buscar a perspectiva dos denominados excluídos, verifica-se que não se constata em seus discursos ou ações a reiteração dos termos que definem em teoria o marginal: o despertencimento, a falta de vínculos, a insuficiência de socialização. Um conjunto recente de estudos, mais interessados no cenário de transformação das periferias paulistanas e cariocas, tem problematizado a suposta desmobilização política das "margens". Diante da emergência de novas formas de regulação da vida social entre as populações pobres - o que Feltran (2008) entende como a expansão do "mundo do crime" - o que é verificado nestas pesquisas são questionamentos sobre as novas formas de constituição da experiência coletiva e da formação dos sujeitos (Machado da Silva 2004; Misse 2006); novas formas de gestão dos espaços urbanos e das condutas individuais (Feltran 2008, 2010a, 2010b; Telles 2010; Marques 2009; Hirata 2010); e ainda, é investigada uma outra política que nasce no interior do crime (Biondi 2010; Biondi \& Marques 2010). 
É seguindo este caminho que o presente texto, ao apresentar um material de pesquisa pouco habitual, busca percorrer um percurso que segue dois eixos analíticos. O primeiro, mais focado na reflexão crítica dos interlocutores, ao apresentar as categorias que decodificam um universo de tensões, discute os mecanismos sociais de reprodução de desigualdades; já o segundo eixo trata do conhecimento necessário para se virar nas ruas, cujo saber indica as formas pelas quais os "moradores de rua" respondem criativamente à mecânica da exclusão, extraindo das relações de força táticas de evasões cotidianas.

A perspectiva aqui adotada, a que privilegia o discurso menor, pretende ainda contribuir, num plano analítico mais abrangente, para a reflexão sobre os conflitos sociais presentes na dinâmica sociopolítica urbana.

\section{O "MORADOR DE RUA" NA OFICINA: DISPUTAS POR LEGIBILIDADEE}

Para evitar falar da rua do ponto de vista da gestão governamental e com isso adotar a expressão "população de rua" - termo que manifesta a lógica de governo ${ }^{6}$ - procurei tratar as trajetórias de rua (Martinez 2011) como expressões da heterogeneidade. Mas, antes de avançar na apresentação do termo "morador de rua", que, como anunciei, é incomum e até contraditório com as variações de suas trajetórias, é necessário fazer uma pequena digressão.

O universo da rua é múltiplo não apenas pela diversidade de perfis, histórias e condições de vida, mas, também, porque uma mesma pessoa pode mudar repetidas vezes. A mudança numa trajetória de rua é provocada quando os vínculos num território são feitos ou desfeitos. Assim, também as diferenciações entre os sujeitos que vivem nas ruas ocorrem a partir do tipo de movimento que realizam. A classificação dos atores varia entre dois pontos fixos: o deslocamento entre territórios e a fixação territorial. Neste sistema classificatório, o termo trecheiro indica o ponto máximo da mobilidade e pardal o ponto mínimo. Contudo, estas categorias não formam a identidade do sujeito porque há sempre a possibilidade deslizar entre o ponto máximo e mínimo, a depender do tipo e da quantidade de vínculos que são estabelecidos com pessoas e lugares. Como não há identidades atreladas aos sujeitos em si, o que produz uma pessoa, do ponto de vista de trecheiros e pardais, são os deslocamentos e os respectivos vínculos produzidos e dissolvidos nos territórios. É como se as próprias relações que os atravessam constituíssem suas pessoas.

No sistema trecheiro, a operação de decompor-se em muitos ${ }^{7}$ (isto é, de produzir e desfazer vínculos) Ihes dá a possibilidade de pulverizar-se no tecido social, enquanto que, ao eleger uma única categoria para falar de si - neste ponto talvez a expressão "morador de rua" possa estabelecer alguma conexão de sentido - arrisco dizer que, ao contrário da primeira operação, provoca uma recomposição do sujeito. A desfragmentação da pessoa é importante para a dispersão, como uma tática de invisibilidade, já a recomposição lhes traz a possibilidade efetiva de tornar-se visível. É neste ponto que a homogeneidade lhes é interessante: porque ao se tornarem um, tornamse também legíveis. 
É a partilha de experiências no mundão, e não em outro "mundo", que faz unir as trajetórias de rua e que torna 'inteligível' um discurso comum, não porque seja uníssono ou sem ruídos, mas porque comunga de um mesmo intento, a saber, é o discurso que desejam transmitir à sociedade e também a $\mathrm{mim}^{8}$; de modo que também eu, na ocasião oficineira e pesquisadora, sou vista por eles como alguém que poderá levar à sociedade a realidade do mundão. O que aparece é um discurso com apelo humanista que traz à tona o preconceito e o sofrimento de quem vive nas ruas. Com isso, passam a conferir sentido à experiência da exclusão da qual anunciam ser vítimas.

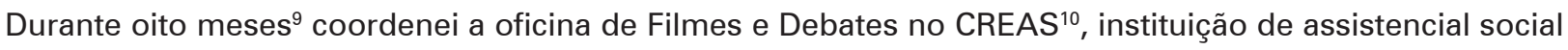
para a população de rua de São Carlos, onde fiz parte da pesquisa de campo. A oficina era o espaço que me foi concedido pela equipe profissional para realizar uma pesquisa sobre o atendimento assistencial da população de rua local. Como eu pretendia construir as atividades de forma conjunta, pedi aos participantes (usuários do CREAS ${ }^{11}$ ) para escolherem os filmes que entrariam na programação das oficinas. Disseram-me que seus preferidos são os que "retratam a realidade". Dentre eles, foram citados alguns títulos da filmografia brasileira mais recente ${ }^{12}$, que retomam no cinema a temática da exclusão social e da marginalidade. Na linguagem cinematográfica, a abordagem do tipo realista, muito presente nos títulos por eles escolhidos, toma como pressuposto que o real é esteticamente próximo à linguagem da cultura (as cores, os sons, a linguagem verbal e corporal). Em Cidade de Deus (2002), Carandiru (2003) e Tropa de Elite (2007), só para citar alguns dos filmes que assistimos nas oficinas, o cotidiano e as tramas das periferias são retratados de forma bastante detalhista, com a utilização de recursos visuais que exploram os pormenores das cenas dos furtos, assaltos, consumo de drogas, as relações entre traficantes e moradores locais, o conflito com a polícia e a vida no cárcere. Para os participantes da oficina, os detalhes e o tipo de abordagem presente nestes filmes retratam nas telas a realidade, da qual também dizem ser testemunhas.

O termo "morador de rua" foi mobilizado nas discussões apenas quando os participantes reclamaram sobre os problemas enfrentados após começarem a viver na rua, como as violências policiais, as más condições de vida, a privação de direitos e o preconceito. Para eles um limiar marca o antes e o depois da rua, em cujo limite constata-se a perda de alguns direitos fundamentais: o de ir e vir na cidade, o acesso a serviços públicos, a integridade física e moral garantida. Por estas e outras perdas, o termo "morador de rua" passa a codificar algumas alteridades, cujo regime de diferenças é marcado pelos limites do pertencimento e da exclusão social. Em outras palavras, é a cidadania que eles afirmam ter perdido.

É importante deixar claro que as reivindicações e as críticas apresentadas no discurso do "morador de rua", e não no discurso de trecheiros e pardais, são escolhas de certos traços diacríticos que lhes permitirão distinguir, por oposição, a cidadania que perderam da indigência, condição que agora afirmam estar. 


\section{A VERDADEIRA REALIDADE DAS RUAS: REGIMES DE ALTERIDADES E PRODUÇÃO DE VERDADE}

A rua é o território que constrói e sobre o qual é construída a percepção dos "moradores de rua" sobre a experiência do social. Para o entendimento das formas de exclusão que serão esboçadas neste texto, a rua designa dois aspectos. Por um lado, a rua abre novos caminhos para os "desajustados". Na perspectiva que reforça a dissimetria social, a rua descrita pelos interlocutores é o espaço reservado àqueles que já foram apartados de dinâmicas sociais integradoras, foram excluídos do mercado de trabalho, da comunidade e da família. Muitos dizem que "acabaram" nas ruas ao fugirem de prisões ou de hospitais psiquiátricos, depois de muitas passagens por estas instituições fechadas ${ }^{13}$. Outros deixaram a comunidade a qual pertenciam porque agiram em desacordo com as recomendações de condutas ligadas ao $\mathrm{crime}^{14}$. Em muitos casos foram expulsos de (ou deixaram a) casa por causa do uso abusivo de drogas. E ainda, muitos vão para as ruas para escaparem das prestações de contas em instâncias burocráticas estatais (tribunais de justiça, por exemplo).

Por outro lado, a rua é lugar do confronto de toda ordem: os verbais, os físicos, os institucionais, as posturas corporais, os desvios de rotas. Esta percepção veio à tona com os relatos sobre as inúmeras e quase sempre negativas reações provocadas no encontro das pessoas que vivem nas ruas com os demais atores. A figura do "morador de rua" codifica em seu corpo e sua existência um sem número de problemas: o da gestão governamental para a prefeitura municipal, o do perigo para os agentes policiais, o da miséria, o da vagabundagem, o do fracasso pessoal, o da doença. O imaginário construído sobre a vida nas ruas é de uma experiência existencial radical que expõe da forma mais crua os conflitos e dramas sociais e individuais.

A dimensão do conflito no cotidiano das ruas é central para o entendimento das práticas de eliminação dos indigentes no cenário urbano, o que faz crescer ainda mais o peso simbólico das experiências vividas nesse espaço. As práticas de extermínio à população de rua, tão recorrentes no Brasil, lançam luz sobre o que De Lucca (2009) entende como a lógica de deixar morrer: é o poder que efetua um corte entre quem deve viver e aqueles que podem morrer ${ }^{15}$. Esta lógica explicita o valor das vidas de rua e os sentidos atribuídos ao espaço público.

A conduta mais explícita da tentativa de aniquilamento dos "moradores de rua" da cidade, nítida porque quase sempre usa da agressão física, provém da atividade policial. Estendendo um pouco a questão, também Telles e Hirata (2010) verificaram as práticas de extorsões e agressões policiais em bairros de periferias. A semelhança do caso das ruas com as rotinas do trabalho policial em comunidades sugere que há na prática policial a incorporação da violência, o que os autores denominam de violência extralegal (Telles e Hirata 2010: 43); quer dizer, é a assimilação de uma espécie de licença para matar, sem, contudo, existir legalidade para a ação. Por isso, também os "moradores de rua" acreditam que a violência provinda dos policiais evidencia não apenas a hostilidade militar, mas, também a ideia já convencionada de que estas vidas podem e devem ser eliminadas.

Na prática de extermínio são identificados os sinais diacríticos da segurança e do risco - o par que configura o modelo dos mecanismos de segurança. No discurso dos "moradores de rua", os policiais, ao receberem treinamento 
de guerra, são instruídos a eliminar os marginais, em cuja figura do "morador de rua" encontram o protótipo mais radical. Também fica claro para as pessoas que vivem nas ruas que suas vidas representam ameaça aos "cidadãos", para quem a polícia, de fato, oferece proteção.

A contradição intrínseca na conduta policial, além de servir como exemplo de um poder bastante contundente, revela as incoerências do exercício e do fundamento das leis civis: a justiça é improcedente e a lei só garante o direito de alguns. A injustiça, a corrupção e a força, expostas de forma tão evidente nas ruas, indicam, para eles, os indícios do verdadeiro funcionamento das relações humanas. É como se as relações sociais, tal como a experimentam nas ruas, estivessem em seu estado bruto.

A partir deste diagnóstico, os "moradores de rua" afirmam ser possível extrair uma verdade sobre as relações humanas. A realidade tem relação direta com a verdade porque esta só pode emergir do conflito. Quando não existe enfrentamento não é possível ser revelada a verdade sobre as coisas. Em ocasiões nas quais o conflito aparece turvo, o que se tem é uma versão falsa da realidade. A interpretação sobre a rua, o local onde é vivida a verdade, é feita em oposição aos espaços sociais onde existem mediações entre as relações sociais. A casa, a escola, o ambiente de trabalho, todos estes, além de outros, são locais onde as desigualdades sociais não são vistas de forma escancarada, de modo que ali os embates são abafados. Diferente do que ocorre no espaço público, as assimetrias não aparecem nestes lugares porque existem sempre critérios selecionando seus públicos. O convívio em ambientes protegidos, ao contrário da rua, é restrito aos iguais, isto é, aos cidadãos.

A partir da oposição de duas dimensões socioespaciais, os "moradores de rua" situam-se no corpo social e constroem uma visão de mundo. Ao colocar em confronto dois domínios, os "moradores de rua" produzem uma noção sobre realidade e verdade. Para eles, a grande diferença entre o que é vivenciado nos espaços de mediação e o espaço onde as relações estão in natura é que no primeiro predomina uma versão falsa de como as coisas funcionam, enquanto que no segundo existe a possibilidade efetiva de ter acesso ao corpo social em funcionamento.

Se não há conflito exposto nas relações sociais, a representação da sociedade está esvaziada de sentido. A conjugação entre os termos verdade e realidade, mutuamente ligados pelo conflito, permite estabelecer uma comparação entre dois mundos: o mundo daqueles que vivem a realidade e daqueles que vivem fora dela.

A realidade, como é vista pelos "moradores de rua", é desconhecida no outro lado. O que prevalece nos outros espaços é uma versão distorcida. Como a verdade é fabricada na prática do cotidiano em luta, a interpretação da realidade, quando feita por aqueles que não vivem em seu dia a dia o conflito, é equivocada.

$\mathrm{O}$ conhecimento produzido de forma indireta e distanciado da realidade - o conhecimento do pesquisador, por exemplo - não possui o mesmo estatuto de verdade para eles. Embora haja aqui uma distinção marcante entre a prática da experiência (entendida como real) e a prática intelectual (entendida como ficcional) ${ }^{16}$, não é qualquer tipo de experiência que promove a verdade. Apenas as vividas no meio marcado pela violência e miséria são capazes de revelar o verdadeiro sentido das coisas.

Os sentidos atribuídos ao espaço da rua estão em disputa em uma arena muito mais ampla e da qual os “moradores de rua" certamente são atores em destaque, mas não são os únicos. Se analiticamente podemos 
pensar a rua como território de um saber, é preciso dizer que ela também vem sendo investida de significados entre jovens de periferia (Guasco 2001; Gimeno 2009; Bertelli 2012). Num estudo sobre os rappers de São Paulo, Guasco (2001) mostra como a rua ganha centralidade na produção musical do movimento hip hop, de modo que ela também aparece como lócus da verdade. Para eles, a rua é o lugar da experiência diante do social, é cenário das violências, apartação e morte, por isso, é o espaço onde o indivíduo defronta-se com a sociedade ${ }^{17}$. $\mathrm{O}$ conhecimento transmitido pela escola (um espaço social oposto à rua) não possui o mesmo valor que o saber produzido nas ruas, isto porque, na sala de aula são omitidos os fatos que revelaram o verdadeiro funcionamento social. A apresentação parcial dos modos pelos quais funciona a sociedade, como por exemplo, a omissão das desigualdades de classe, provoca a descrença destes jovens no conhecimento considerado legítimo.

A rua é também o lugar do confronto social, sobretudo porque se verifica a partir dela a diferenciação entre os portadores de direitos e os desprovidos. Vivendo num cotidiano de desventuras, seja quando fogem da polícia, quando pedem dinheiro e comida ou quando são expulsos dos locais, os "moradores de rua" elaboram, com base nestas ocasiões desfavoráveis às suas existências, um diagrama no qual são demarcadas as fronteiras de quem está dentro e fora da sociedade.

Ser cidadão significa para eles fazer parte da sociedade, enquanto que a indigência marca uma oposição diametral ao primeiro termo. A oposição entre o cidadão e o não-cidadão é marcada por uma diferenciação construída nos termos outros e nós. Assim, o modo como são tratados no espaço público compõe os parâmetros do que é a definição da ausência de cidadania e, por oposição - ou seja, aquilo que lhes falta - constrói uma ideia do que seria um sujeito cidadão, os outros. Relatam situações que só começaram a ocorrer quando iniciaram suas trajetórias de rua, como por exemplo, apanhar da polícia sem ter cometido nenhum desacato aparente, ser impedido de entrar em alguns estabelecimentos comerciais, não conseguir comprar algo porque os comerciantes se recusam a realizar a venda. Todas estas situações marcam os limites que circunscrevem a cidadania (a vida dos outros) e a indigência (a nossa vida).

O relato das práticas de extermínio na rua contribui para o argumento de Feltran (2007), que entende a violência como o fundamento da construção do modelo recente de ação política oficial. Para o autor, a violência direcionada às populações pobres não é um "desvio" da democracia, isto porque uma fronteira separa os que podem gozar do direito e todos os outros que ameaçam a ordem e, por isso, precisam ser reprimidos.

\section{DO PONTO DE VISTA DE QUEM VIVE NO MUNDÃO: AS DISSIMETRIAS EM PERSPECTIVA}

Como o discurso aqui apresentado está implicado na ação política, o narrador deste enredo aparece muito bem demarcado: é aquele que vive no mundão e conhece a realidade. Na narrativa, o mundão é o espaço real dos conflitos, mas, não apenas, ele indica também uma cosmovisão (o ponto de vista do narrador). O vocábulo mundão expressa um mundo em sua forma superlativa, não porque seja grande em extensão (em seu sentido denotativo), 
mas porque o termo aparece como um mundo concreto visto além das aparências. A realidade revela uma verdade velada: é um mundo de relações hostis, da fome, da repressão, assim, o chamam também de mundo-cão. Contudo, este mundo, no qual os conflitos tornam inteligíveis as relações sociais, é reservado apenas aos apartados da sociedade. A partir desta verificação, o funcionamento social pode ser explicado pelo jogo da diferença, cujo resultante é a desigualdade.

Constata-se neste argumento uma leitura sobre a produção da dissimetria, verificada e vivida no cotidiano. Para os narradores deste enredo, os que conhecem a realidade, o produto das relações sociais é a disparidade. 0 que para eles é visto como um processo claro, para outros - os que não têm conhecimento da realidade - a verdade é escondida. Ao discursarem sobre o funcionamento das relações sociais, cujo tema parece não haver consenso entre as partes, é detectada a verdade sobre a sociedade: a divisão entre grupos.

Se na descrição etnográfica a sociedade é um conjunto de relações em constante tensão, cuja forma verdadeira é cindida, no plano analítico a categoria se assemelha ao que Rancière (2005) esboça como o comum, o "lugar" de disputa onde se explicita a subjetividade da política. A cisão que anunciam aproxima-se do que o autor entende como partilha, cujo caráter sempre polêmico, assinala a tensão entre o que divide e o que une um comum (simultaneamente participação e apartação). Seguindo o argumento de Rancière e dos "moradores de rua", a sociedade pode ser entendida como um território de disputas uma vez que é o "lugar" por excelência da visibilidade e da plenitude do cidadão, em cuja esfera eles não se sentem incluídos.

A primeira e mais fundamental das divisões que incide sobre o corpo social é aquela que eles experimentam diariamente: a incisão provocada pela posse ou desprovimento de direitos. Em momentos anteriores assinalei que a figura do cidadão é a alteridade máxima dos "moradores de rua", logo, a ausência quase completa de direitos configura a maior das dissimetrias. A diferenciação entre cidadão e indigente, para eles o marcador das alteridades, confere inteligibilidade à divisão social e manifesta a natureza bipartida da sociedade. A fragmentação social é composta ainda por outras derivações: a diferença entre o branco/preto e o rico/pobre. Todas essas disparidades, além de outras que não cabem na economia deste texto, marcam fundamentalmente os desequilíbrios de forças da sociedade. As dessemelhanças são provas reais de que as relações sociais produzem um mundo disforme que é desconhecido por quem não tem acesso ao estado real das coisas.

A revelação da verdade sobre as relações sociais pode ser manifestada no momento em que os "moradores de rua" pedem dinheiro. Contudo, diferente da representação feita pelo senso comum, pedir dinheiro, para eles, é uma técnica de "fazer" dinheiro, também chamada de mangueio. Os pedidos ocorrem por meio de um discurso que enuncia o mundão, através do ato mesmo que cristaliza a diferença entre o pedinte e o doador - aquele que tem dinheiro e o que não tem. O mangueio, apesar de reforçar a assimetria, possibilita uma troca material e subjetiva entre dois mundos. Para "fazer" dinheiro, o objetivo principal do mangueio, o pedinte aciona em seu discurso alguns elementos que modelam uma imagética da pobreza, como forma de sensibilizar o doador e convencê-lo a doar.

Ao elaborar um discurso em torno da fome, do frio, das chagas (recursos escolhidos de forma tática), uma representação sobre a vida nas ruas é construída e enunciada ao abordado. No discurso do mangueio são tomados 
de empréstimos conteúdos do repertório sociocultural das ruas para enunciar os estigmas e privações, com o intuito de compor os estereótipos da miséria e explorar as imagens recorrentes de como são vistos e tratados.

Uma interlocutora de pesquisa - cuja trajetória de rua se iniciou com programas de prostituição como travesti e depois de ser expulsa do local onde vivia acabou sendo atendida na instituição de assistência social para a população de rua da cidade - serve como exemplo para pensar o mangueio como arte de sensibilizar o outro e como enunciação. Ao acompanhá-la na rua em uma tarde, ela vai até a porta de uma churrascaria para manguear. $\mathrm{Na}$ abordagem aos clientes que entram ou saem do estabelecimento, ela escolhe exatamente os elementos que reificam seus estigmas, para chocar e também convencer o outro de sua condição:

Moço, dá uma moedinha pra mim? Eu tô na rua, sou travesti, tô com fome, fui expulsa de casa porque eu sou viado. O senhor não tem uma moedinha pra eu comprar pinga? Eu to com frio, num é fácil morar na rua, só bebendo pra esquecer os problemas (Diário de campo 04/04/2011).

A narrativa do mangueio possui dupla eficácia: a primeira, sendo literal, apresenta ao suposto doador as condições reais das ruas, explorando as imagens da precariedade e da miséria com o objetivo de enunciar com fidelidade o mundo da pobreza. A segunda é emotiva, buscando envolver o doador com o conteúdo transmitido e sensibilizá-lo através das figuras da indigência. Para quem vive nas ruas, os termos acionados Ihes são óbvios porque são parte do mundo concreto, mas, como enunciado, servem para chocar o outro revelando um conteúdo inédito.

Entre o pedinte e o doador existe uma alteridade que é produzida pelo afastamento das realidades. Em outras palavras, o doador é o outro uma vez que ele encontra-se fora da realidade, não conhece o mundão. 0 dissenso entre uma realidade e outra é verificada no modo pelo qual o conflito é conhecido. De um lado, é vivido na prática, do outro, o conflito é conhecido por outras vias que não a experiência concreta. Para eles, a divisão não é marcada apenas por um choque entre perspectivas. Portanto, não se trata da maneira como cada um dos lados "entende" a sociedade, mas do modo como se "vive" na sociedade - este sim demarca uma diferença descomunal.

Ao se apoiar na ideia de um corpo social dividido, o argumento defendido por aqueles que vivem no mundão contrapõe-se vigorosamente ao discurso moderno sobre sujeito universal de direitos ${ }^{18}$. Os "moradores de rua" não acreditam em valores universais porque no mundo concreto (na realidade) a paz, a justiça, a liberdade e a igualdade são meras abstrações que, para eles, não possuem nenhum correspondente real. Como o mundão funciona sob outros valores, acreditar, por exemplo, que a igualdade é aplicada concretamente é uma ideia falsa e ingênua sobre a realidade.

O afastamento das realidades, ou a divisão entre os mundos, promove um descentramento que opera duplamente: o primeiro incide sobre o corpo social (na sociedade, como dizem), é a incisão que produz posições marginalizadas; o segundo provoca efeitos no ponto de vista, já que se passa a enxergar o mundo de modo diferenciado - fato que, para eles, é algo positivo, pois é deste descentramento que a verdade sobre as coisas é arrancada. Acreditar em uma sociedade entre iguais - possível leitura dos outros sobre o mundo - pode ser, para os "moradores de rua", uma convicção astuta porque produz uma verdade fraudulenta e esvazia os sentidos do embate, algo que para eles é de fundamental importância. 
A descrença nos valores universais previstos nos direitos humanos é também manifestada em outras conjunturas parecidas com as da rua, para manter apenas a discussão no campo da etnografia urbana. Em pesquisas recentes ${ }^{19}$ que revelam novas formas de políticas gestadas no seio do crime (Marques 2009, 2010; Biondi 2010, Marques \& Biondi 2010; Hirata 2010) este sistema de governo opera sob as mesmas noções de direito (paz, justiça, liberdade e igualdade), mas as codificam num registro nada universal. Os presos, os rappers e os jovens de periferia - citando apenas alguns dos personagens nos quais é identificado um contradiscurso jurídico - reivindicam para si novos sentidos do direito. Não é um direito universal porque a igualdade não se processa na prática, mas um direito entre iguais - entre "homens de proceder" (Marques 2010).

Os "moradores de rua" não são os únicos a terem acesso à realidade. O mundão é conhecido e vivido por todos aqueles que são atravessados pelas relações de força e sofrem os efeitos da apartação social. Para os que conhecem o mundão, a vida é entendida como uma guerra. A analogia aparece de forma muito incisiva na expressão vida loka ${ }^{20}$, cantada pelos rappers e comumente utilizada nas periferias paulistanas. Ela comunica a ideia de que as práticas e relações sociais estão em perpétuo desequilíbrio, assim, a vida constitui-se no caos. O que se verifica entre os que vivem na vida loka e os que vivem no mundão é que, de forma quase análoga, ambos percebem o mundo em estado desordenado e enfrentam os dramas cotidianos.

\section{COMO SE VIRAR NAS RUAS: MODOS DE EMPREGAR TÁTICAS E DE CRIAR RESISTÊNCIAS}

Os sentidos do embate apurados na realidade e no mundão dos "moradores de rua" engendram diferentes e criativas respostas às forças que os atravessam, incitam modos práticos de subterfúgios derivados de circunstâncias perigosas do cotidiano. Analiticamente, estes modos de fazer proveniente das ruas podem ser lidos como táticas inspiradas em Michael De Certeau (1998) - filósofo que, ao dedicar generosa atenção ao agir do homem comum, atribuiu um estatuto epistemológico às "maneiras de fazer cotidianas". As táticas são maneiras de utilizar o sistema e suas imposições, constituindo resistências entre forças desiguais; são modos de empreender combates despropositais para forjar as regras de um contrato social favorável aos mais fortes. Para seguir adiante com a inscrição do material de pesquisa na teoria das práticas cotidianas, não basta entender as táticas apenas como um produto intelectual repentino; são improvisos, mas também são conhecimentos profundos das relações de força no qual os atores estão inscritos. A vantagem analítica em dar atenção às táticas é que elas permitem compreender o que ocorre nos espaços sociais nos quais artifícios silenciosos jogam com o sistema dominante.

Em termos etnográficos, as inventivas manobras compõem um conhecimento produzido na urgência, no cálculo rápido e imediato, quando os "moradores de rua" enfrentam o perigo, conhecimento chamado por eles de maneiras de se virar nas ruas. Não seria exagero afirmar que estes saberes em favor da vida são uma "arte da resistência", são "inventividades dos fracos", no sentido que De Certeau (1998) mobiliza para falar das subversões dos desprivilegiados. Muito embora existam diferenças nas trajetórias de rua, o aprendizado para se virar nas ruas, 
por ser uma pedagogia do imprevisto, cabe a todos os que vivem no mundão. Portanto, as táticas são respostas corporais e diárias ao sistema hegemônico sem, contudo, confrontá-lo de forma direta.

Para viver no mundão é necessário ter um olhar atento aos fluxos, regras e valores do cotidiano. Os "moradores de rua" apropriam-se das formalidades dos signos e deslocam para outros terrenos os sentidos convencionalmente produzidos. Deste modo, estes artesões empregam uma multiplicidade de práticas que atuam nos detalhes. Quando os "moradores de rua" andam pela cidade observam os signos arquitetônicos e urbanísticos com um olhar meticuloso. Procuram por lugares que possam ser utilizados como esconderijos. Chamam de mocós quaisquer lugares onde possam esconder-se: casas abandonadas, terrenos baldios, estabelecimentos desativados, posto de gasolina, praças, árvores ou buracos quaisquer. Para um lugar virar um mocó é avaliada a segurança da área, levando em conta os riscos de desabamento, a desocupação efetiva do local, o fluxo de pedestre nas redondezas, o policiamento da área, as atividades comerciais realizadas nas proximidades. Todos estes critérios são ponderados para terem a garantia de que não serão vistos por muita gente. A discrição é importante porque, para eles, não atrair a atenção dos olhares é uma das poucas maneiras de passarem despercebidos pela cidade e assim pouparem-se dos perigos.

Os refúgios lhes são essenciais para assegurar o mínimo de proteção. Na escuridão da noite, quase sem testemunhas oculares, ocorre a maior parte dos atentados contra as pessoas que vivem nas ruas, por isso cada um deve procurar um local seguro para dormir ${ }^{21}$. Ao relento estão vulneráveis a espancamentos, abusos sexuais, roubos, assaltos, abordagens policiais, expulsão dos locais onde descansam. A proteção pessoal é feita com os poucos recursos materiais que possuem. Não basta manterem-se fora do alcance dos olhares, os "moradores de rua" ainda carregam consigo alguns utensílios como facas, lâminas, pedras, qualquer ferramenta que possa servir como arma, caso sejam atacados por alguém.

Como os mocós são locais imperceptíveis aos olhos desatentos, são espaços ideais para o consumo de substâncias psicoativas sem correr o risco de ser pego pela polícia. Mas a preocupação não se limita à apreensão policial, já que sob o efeito de drogas, os interlocutores dizem que podem perder a capacidade de cuidarem de $\mathrm{si}^{22}$. O cuidado que cada um deve ter consigo exige o emprego de algumas táticas, entre elas o cuidado com o corpo. Beber muita pinga ou fumar muita pedra (crack) são considerados descuidos, de modo que a alteração da consciência provocada por estas substâncias diminui a capacidade de defesa pessoal. São frequentes os casos em que os "moradores de rua" ficam muito chapados ${ }^{23}$ e são atropelados nas vias de trânsito; têm seus documentos, dinheiro e mochilas roubados; apanham de outras pessoas ou, então, provocam brigas que geralmente terminam em agressão física ou mesmo em morte. Escondidos de tudo e de todos, nos mocós estas pessoas estão em resguardo.

Todos os equipamentos urbanos são taticamente avaliados segundo as possibilidades que as pessoas que vivem nas ruas compreendem para seu uso. As táticas são operações que extrapolam os produtos da convenção, elas seguem os vestígios das formalidades práticas para inventar formas inéditas de uso. As praças, por exemplo, ao contrário do emprego comum que se faz delas (um local de passagem), são espaços onde as pessoas que vivem nas ruas bebem pinga, jogam cartas, fumam em roda e conversam. Todas as instalações locais são também 
utilizadas de forma criativa. Os bancos podem servir-Ihes de repouso e as sombras das árvores são disputadas entre eles para um cochilo. Os galhos das árvores são também utilizados para esconder suas mochilas, sacolas e pertences pessoais.

No universo da rua, estes atores são especialistas em mapear pontos estratégicos, identificando os melhores lugares para manguear, receber doações, descansar em segurança, beber e fumar sem incômodos. Assim, eles realizam uma leitura minuciosa e precisa dos signos urbanos. Os locais de intenso trânsito de pedestres são os mais apropriados para manguear. No Mercado Municipal, localizado na área central da cidade de São Carlos, o fluxo de pedestres é grande, por isso é considerado o melhor ponto para conseguirem rapidamente alguns trocados. A rodoviária é um espaço onde muitos "moradores de rua" recorrem para manguear. Por ser um local de embarques e desembarques, dizem que precisam de dinheiro para viajar, argumento que quase sempre convence o doador.

Um pardal que conheci na rua, de tanto andar pelo centro da cidade, desenvolveu uma tática para conseguir alimentar-se todos os dias sem gastar nenhum dinheiro. Ele descobriu o melhor horário para conseguir doações de comida nos restaurantes sem incomodar os comerciantes ou os fregueses dos estabelecimentos. Disse-me que, de manhã, pedia nas padarias os pães do dia anterior. No almoço, visitava os restaurantes após as 14 horas, horário em que encerrava a venda das refeições. Um vendedor ambulante de pastel lhe dava alguns depois das 17h30, perto do horário em que encerra seu expediente de trabalho.

Atentos em tirar proveito das situações que muitas vezes lhes são desfavoráveis, os "moradores de rua" educam-se pela atenção. Os modos de agir diante das adversidades são habilidades importantes e necessárias para se virar nas ruas. Como o mundão exige aptidões específicas para se adaptar aos conflitos, a aquisição deste conhecimento ocorre na medida em que o sujeito vivencia cada vez mais situações de perigo ou privações e extrai delas os modos de evasões. Quando as táticas são bem assimiladas, o "morador de rua" aprende a lidar com circunstâncias nas quais a própria vida está em jogo. Dizem que o "cara sabe se virar" quando são utilizadas as táticas para contornar a maior parte das situações desfavoráveis com que se deparam. Mais do que isso, a expressão indica os modos de gestão da própria vida. Quem sabe se virar nas ruas domina as táticas de defesa e cuidado pessoal, de aquisição de bens materiais, de mangueio, de mapeamento dos locais para sua acomodação. Digo que as táticas são habilidades de autocuidado porque, para eles, quem sabe se virar pode ser considerado um sujeito com autonomia. A noção de autonomia empregada nas ruas não remete de modo algum à ideia de cidadão, como é entendida pelas instituições que cuidam da população de rua ${ }^{24}$. De outro modo, um ser autônomo é aquele que possui capacidade de autogovernar-se, incluindo, aliás, táticas de utilização da rede assistencial ${ }^{25}$.

O conhecimento produzido nas ruas fabrica sujeitos em alerta, é o "cara ligeiro", para manter a expressão da rua. As táticas são ensinamentos para (sobre)viver no mundão. Não é á toa que, com tantos perigos a serem driblados, quem aprende a desviar dos inúmeros contratempos são consideradas pessoas que, apesar de tudo, conseguem preservar sua própria integridade. Neste sentido, este é um saber de resistência, é a arte da insubordinação dos fracos.

Mariana Medina Martinez é mestre em Antropologia Social pela Universidade Federal de São Carlos e atualmente doutoranda nesse mesmo Programa de Pós-Graduação. 


\section{NOTAS}

1 Este artigo é uma versão revisada do paper apresentado no GT Antropología de las periferias urbanas: transformaciones socioterritoriales, desigualdades en la ciudad y nuevos conflictos en el espacio público, coordenado por Neiva Vieira da Cunha (UERJ e UFRJ/LeMetro), María Carman (Conicet), Gabriel Feltran (UFSCar), na IX Reunião de Antropologia do Mercosul, realizada em julho de 2011. Devo agradecer imensamente aos colegas do Na Margem: núcleo de pesquisas urbanas (UFSCar) que fortificaram as discussões deste trabalho.

2 Os resultados apresentados neste texto são provenientes de uma pesquisa desenvolvida durante o período de Mestrado realizado no Programa de Pós-graduação em Antropologia Social da Universidade Federal de São Carlos.

3 Em trabalhos anteriores argumento que existem diversas formas de viver nas ruas. Como recurso metodológico e analítico para tornar efetiva a descrição da diversidade, trato das trajetórias de rua, que são compostas pelas relações que conectam os sujeitos com os territórios. É a falta de constância que possibilita uma trajetória transformar-se repetidas vezes, como uma tática para se esquivar das interpelações cotidianas. Por isso, as variações constantes em uma trajetória são importantes e indispensáveis para a preservação da própria vida. É neste sentido que a característica anti-identitária das trajetórias de rua aproxima-se do protótipo nômade, no sentido mesmo em que Deleuze e Guattari (1997) elaboram para argumentar sobre um paradigma da ação política, chamado por eles de "máquina de guerra".

4 A noção de minoria em Deleuze \& Guattari (1995) está intimamente relacionada à maioria, mas não sob o aspecto quantitativo. A maioria implica um estado de poder e de dominação cujo conteúdo é avaliado como um padrão, isto é, um sistema hegemônico e constante. Tudo aquilo que é colocado fora do padrão é considerado minoritário. Assim, este último seria como subsistemas, por isso, possui um devir potencial criativo. Mas o menor não existe por si. Ele só existe em relação ao maior, por investimentos que possam tornar algo menor em relação ao padrão. A relação entre maior e menor pode ser encontrada em diversos aspectos na literatura, na política, na linguística, nas formas jurídicas. Um saber quando considerado menor, diferente do saber científico que é padrão e, por isso, maior, possui uma potência de variação, é como se fosse uma utilização dos padrões, mas de forma variável.

5 Foucault (2005 [1976]) sugere que os saberes sujeitados são conteúdos históricos mascarados pelos saberes científicos; são memórias locais apagadas pela erudição. O projeto da genealogia, utilizado como método de investigação em suas obras, consiste na reativação dos saberes locais contra a hierarquização científica do conhecimento e seus efeitos de poder intrínsecos. Foucault não pretende de modo algum dar um tipo de coroamento teórico que possa unificar os saberes científicos e os sujeitados. Sua proposta é precisar ou delinear o que está em jogo nessa oposição, por em contraste os saberes e verificar os efeitos de poder do discurso científico.

6 Ao buscar inventariar o Estado Moderno, Foucault (2008 [1978]) aponta que em meados do século XVIII surge uma nova "arte de governar", chamada de governamentalidade, que denomina um conjunto de instituições, estratégias e mecanismos que exercem um poder sobre a vida humana. Diferente do poder disciplinar, o biopoder que emerge no modelo da sociedade da segurança, dirige-se fundamentalmente ao homem, não enquanto indivíduo ou corpo, mas como espécie. A emergência do fenômeno "população" permitiu o exercício de mecanismos de controle sobre os processos que atravessam a espécie humana, a reprodução, natalidade e a mortalidade, garantindo certos padrões dessa reprodução.

7 Estudos melanésios poderiam servir de modelo comparativo para pensar os modos de funcionamento do sistema trecheiro, os quais propõem um modo de pensamento mais holista para superar a obsoleta mecânica do indivíduo/sociedade. O conceito de pessoa implicado nesta contrapartida holista é denominado por Wagner (1991) de pessoa-fractal. A ideia de fractalidade nunca é uma unidade em relação a um agregado, mas sempre uma entidade cujas relações estão integralmente implicadas. Para discussão de noções de pessoas dividuais ver Strathern $(1991,2006)$ e sobre o híbrido homem-máquina ver Haraway (1985).

8 Essa percepção veio à tona ao ler um texto de Karina Biondi que circulou entre os membros internos do grupo de pesquisa Hybris, do qual somos participantes. Também nas quebradas, o discurso sobre o crime aparece de forma legalista, enfatizando as más condições do sistema carcerário, da pobreza e da violência policial. Não condiz, portanto, com o discurso que interessa à dinâmica política interna do crime.

9 Os encontros das oficinas eram semanais e ocorriam sempre no CREAS.

10 O CREAS é uma unidade pública estatal de prestação de serviços de proteção social especial de alta complexidade. Em São Carlos a instituição tem o atendimento exclusivo à população de rua da cidade. 
11 O público atendido pelo CREAS é composto pela população de rua da cidade (grifos meus). Este é um critério que diferencia os itinerantes e a população de rua local. Para ter direito ao atendimento os critérios são: estar em situação de risco pessoal e social, utilizar a rua como moradia ou sobrevivência, ter vínculo familiar ou comunitário no município (Prefeitura do Município De São Carlos 2010: 4). Em 2008 foi realizado um levantamento por Silva e Herrera (2008) cujos dados apontam que 88\% dos usuários do CREAS neste período, são homens com faixa etária entre 25 e 60 anos.

12 A partir da década de 1990, a produção cinematográfica nacional passou por uma "retomada" do tema favela. Cidade de Deus (2002) é o filme de maior destaque desta geração do cinema. A periferia volta às telas com a diferença na abordagem e nos modos de retratar este espaço urbano. Criam-se novas práticas estéticas que investem no reconhecimento da "realidade social". O esforço é dedicado a retratar com fidelidade toda a complexidade da periferia (isto é, a realidade), rompendo com as antigas representações cinematográficas sobre o tema. Nas oficinas que coordenei foram citados alguns títulos que representavam a realidade das periferias: Carandiru (2003), Tropa de Elite (2007), Bicho de Sete Cabeças (2001), Boca de Lixo (1993), Linha de Passe (2008).

13 Um fato curioso nas narrativas de vida das pessoas que vivem na rua é que, embora estejam fora da lógica institucional estatal (por estarem nas ruas), grande parte delas foi internada em instituições fechadas em seu passado. Na Pesquisa Nacional sobre População em Situação de Rua (MDS: 2008), cerca de 60\% dos entrevistados afirmaram já terem sido detidos em instituições como prisão, hospital psiquiátrico, casa de recuperação para dependentes químicos, orfanato, casa de detenção de menores ou abrigo institucional.

14 Os relatos que colhi indicam casos de mancadas nas comunidades. Dar mancada significa agir em desacordo com o proceder. No crime, o proceder é um conjunto complexo de regras que orientam parte significativa das experiências dos presos, traficantes e também moradores da favela. Sobre uma etnografia do proceder, ver Marques (2009, 2010). Em São Carlos, jovens com idade em torno de 18 e 25 anos relatam sobre a regulação das condutas nas periferias da cidade, sugerindo que em casos de litígios serão acionadas instâncias de justiças mediadas pelo crime para julgar o caso. Tomando como base o cenário atual das periferias, sobretudo aquelas sob domínio do crime, quem age em desacordo provavelmente será julgado pelo litígio. Possivelmente os jovens que deixaram suas comunidades para viver nas ruas sofreram algum tipo de ameaça dos sujeitos que mediam o crime no local.

15 De Lucca (2009) busca compreender em Foucault (2005 [1976]) a função de morte no regime biopolítico. Segundo Foucault, o direito de matar só existe no biopoder através do racismo, que possibilita efetuar uma triagem na população (a eliminação da "espécie inferior").

16 A distinção entre experiência concreta (real) e experiência ficcional foi colocada em questão durante as oficinas. Chamou-me a atenção esta distinção num dos debates em que discutíamos sobre a atuação repressora da polícia sobre os moradores de rua. Assim como todos os participantes expuseram sua opinião, fui também falar da minha. Embora não tivéssemos de modo algum argumentos contrários, minha opinião foi considerada menos válida do que a dos demais. Alegaram que eles sabiam bem do assunto porque já haviam vivido na pele, enquanto eu, pouco sabia por que nunca tinha vivido situações como as deles. Nota-se que a experiência concreta é fonte de apreensão de um conhecimento, enquanto que a experiência não-concreta (a aprendizagem através de estudos, por exemplo) proporciona a apreensão de um tipo de conhecimento que é diferente do primeiro.

17 O termo sociedade não aparece em itálico nesta passagem porque se trata do modo como Guasco (2001) trabalhou conceitualmente em seu texto, diferente do modo como optei em descrevê-la. A noção de sociedade aparece em Guasco no sentido que os rappers concedem ao termo, ou seja, é descrita etnograficamente, mas está também situada numa tradição teórica que problematiza a contradição entre o indivíduo e a sociedade.

18 Na filosofia, François Jullien (2008a), ao depurar os universais do pensamento europeu, afirma que a universalidade ocupa um lugar central na legitimação da noção de progresso histórico, do qual os direitos humanos são produto da mais alta escala da civilidade. Os "nossos" universais, como diria o autor, são uma fabricação excêntrica e caótica, oriunda do modo de vida ocidental, da ciência e do capitalismo. Em um artigo, Jullien (2008b) ainda reforça que os direitos humanos são produtos de uma dupla abstração cuja legitimidade está restrita ao quadro ideológico e cultural ocidental: dos "direitos" e do "homem". Sob o estatuto da transcendência e da abstração, os dois conceitos tornam-se manejáveis em outros contextos culturais. A capacidade universalizante dos direitos do homem, que é da ordem prática e não teórica, tem um alcance negativo, de modo que ao serem forçosamente estendidos como enunciado de verdade a todas as culturas do mundo estes conceitos ocidentais impõem uma ética universal.

19 A primeira reunião de diversos pesquisadores de São Paulo e do Rio de Janeiro, cujos trabalhos lançam-se para uma nova abordagem sobre crime e periferia, ocorreu em 2008, no Simpósio de Antropologia: Entre o Legal e o llegal, promovido pelo PPGAS da Universidade Federal de São Carlos. Em 2010, foi organizado por Karina Biondi e Adalton Marques o Dossiê Jovens em conflitos com a Lei, publicado 
na Revista R@u (Revista de Antropologia Social dos Alunos do PPGAS-UFSCar). Os artigos seguem com contribuições sensíveis para o debate em curso.

20 Nas músicas dos Racionais Mc's são encontradas muitas referências para a compreensão da vida loka. Na sociologia e antropologia, alguns trabalhos sobre periferia e crime analisam a expressão. Ver Hirata (2010) e Malvasi (2011a, 2011b).

21 Muitos moradores de rua dormem no Albergue Noturno da cidade. Esta é uma das alternativas para quem procura um local seguro para passar a noite. Contudo, no Albergue não podem fazer uso de bebidas alcoólicas ou drogas, sendo este um dos (muitos) motivos pelos quais alguns moradores de rua não recorrem à instituição.

22 Os moradores de rua afirmavam que é preciso desconfiar de tudo e de todos para sobreviver nas ruas, por isso "cada um cuida de si". A expressão denota, como Foucault (1984) demarca, uma intensificação das relações consigo mesmo, enquanto uma ética de domínio que produz uma subjetividade particular, uma arte que define os critérios éticos da existência. Neste sentido, as práticas de cuidado de si nas trajetórias de rua, sob a luz dos estudos de Foucault, são entendidas como práticas que transformam gradualmente um corpo e um sujeito para formar certo modo de ser que, neste caso, são sujeitos em alerta.

23 O termo chapado indica o uso excessivo de alguma substância psicoativa.

24 A autonomia é uma categoria utilizada no CREAS, e em outras instituições de assistência social e saúde, que opera como um índice de normatização dos sujeitos. Quando a autonomia é recomposta por completo no sujeito, neste caso, o sujeito já está ressocializado. A ideia de ressocialização traz os sentidos da reativação dos laços comunitários, familiares e trabalhistas. No caso deste estudo, "dar autonomia ao sujeito" significa oferecer as condições para que o sujeito saia da rua e não retorne mais a ela.

25 A utilização dos serviços sócio-assistenciais é recorrente entre a população de rua de São Carlos. Contudo, o sentido que empregam para o chamado "vínculo institucional" não é o mesmo para as instituições que os atendem. Quando recorrem aos serviços não quer dizer que os moradores de rua irão substituir a rua pela instituição. Ao contrário, acompanhei muitos casos em que usam a instituição para continuar vivendo nas ruas. Muitos recorrem aos serviços para tirar documentos, lavar suas roupas, comer, descansar. É no sentido de saber utilizar os serviços em favor de si mesmo que os "moradores de rua" elaboram a noção de autonomia. 


\section{REFERÊNCIAS BIBLIOGRÁFICAS}

BERTELLI, Giordano. 2012. Errâncias racionais: apontamentos sobre RAP e política. Paper apresentado no $36^{\circ}$ Encontro Anual da ANPOCS, Águas de Lindóia, SP.

BIONDI, Karina. 2010. Junto e misturado: uma etnografia do PCC. São Paulo: Editora Terceiro Nome.

BIONDI, Karina \& MARQUES, Adalton. 2010. “Memória e historicidade em dois 'comandos' prisionais". Lua Nova 79:39-70.

BRASIL. Ministério do Desenvolvimento Social e Combate à Fome (MDS). 2008. Pesquisa Nacional sobre População em situação de rua. DF.

CALDEIRA, Teresa. 1984. A Política dos Outros: o cotidiano dos moradores da periferia e o que pensam do poder e dos poderosos. São Paulo: Brasiliense.

DE CERTEAU, Michael. 1998. A invenção do cotidiano 1. Artes de fazer. Petrópolis: Vozes.

DELEUZE, Gilles \& GUATTARI, Felix. 1995. “Postulados da linguística”. In Mil platôs: Capitalismo e Esquizofrenia. Vol. 2. São Paulo: Editora 34.

1997. “Tratado da nomadologia”. In Mil platôs: Capitalismo e Esquizofrenia. Vol. 5. São Paulo: Editora 34.

DE LUCCA. Daniel. 2009. Morte e vida nas ruas de São Paulo: a biopolítica vista do centro. Monografia. Departamento de Geografia, Universidade de São Paulo: São Paulo.

DURHAM, Eunice. 1973. A caminho da cidade. São Paulo: Perspectiva.

FOUCAULT, Michael. 1984. História da Sexualidade III - o cuidado de si. Rio de Janeiro: Graal.

Fontes. 2005 [1976]. Em defesa da sociedade: curso dado ao Collége de France (1976-1977). São Paulo: Martins

2008. [1978]. Segurança, Território e População: curso dado ao Collége de France (1977-1978). São Paulo: Martins Fontes.

FELTRAN, Gabriel. 2007. "A fronteira do direito: política e violência na periferia de São Paulo". In E. Dagnino \& L. Tatagiba (orgs.). Democracia, Sociedade Civil e Participação. Chapecó.

2008. Fronteiras de tensão: um estudo sobre política e violência nas periferias de São Paulo. Tese de Doutorado. Instituto de Filosofia e Ciências Humanas, Universidade Estadual de Campinas.

2010a. “Crime e castigo na cidade: os repertórios da justiça e a questão do homicídio nas periferias de São Paulo". Caderno CRH 23: 59-74.

2010b. “Introdução". Lua Nova Revista de Cultura e Política 79. São Paulo.

GIMENO, Patrícia. 2009. Poética versão: a construção da periferia no rap. Dissertação de Mestrado, Departamento de Antropologia: UNICAMP. 
GUASCO, Pedro. 2001. Num país chamado periferia: identidade e representação da realidade entre os rappers de São Paulo. Dissertação de Mestrado. Programa de Pós-Graduação em Antropologia Social: Universidade de São Paulo.

HARAWAY, Donna. 1985. "Manifesto for Cyborgs: Science, Technology, and Socialist Feminism in the 1980s". Socialist Review 80: 65-108.

HIRATA, Daniel. 2010. Sobreviver na adversidade: entre o mercado e a vida. Tese de Doutorado. Departamento de Sociologia: Universidade de São Paulo.

JULLIEN, François. 2008a. O diálogo entre as culturas: do universal ao multiculturalismo. São Paulo: Editora Zahar. 2008b. “Universels, les Droits de I'Homme?", Le Monde Diplomatique, fev.

KOWARICK, Lúcio. 1979. A espoliação urbana. Rio de Janeiro: Paz e Terra.

MACHADO DA SILVA, Luiz. 2004. "Sociabilidade violenta: por uma interpretação da criminalidade contemporânea no Brasil urbano". In Sociedade e Estado 19(1): 53-84.

MALVASI, Paulo. 2011a. Interfaces da vida loka: um estudo sobre jovens, tráfico de drogas e violência em São Paulo. Tese de Doutorado. Faculdade de Saúde Pública: Universidade de São Paulo.

2011b. "Choque de mentes': dispositivos de controle e disputas simbólicas no sistema socioeducativo". R@u - Revista de Antropologia Social dos Alunos do PPGAS-UFSCar 3.

MARQUES, Adalton. 2009. Crime, proceder, convívio-seguro: um experimento antropológico a partir de relações entre ladrões. Dissertação de Mestrado. Departamento de Antropologia: Universidade de São Paulo.

2010. “Liderança, proceder e igualdade: uma etnografia das relações políticas no Primeiro Comando da Capital". Etnográfica 14: 311-335.

MARTINEZ, Mariana. 2011. Andando e parando pelos trechos: uma etnografia das trajetórias de rua em São Carlos. Dissertação de Mestrado. Departamento de Ciências Sociais: Universidade Federal de São Carlos.

MISSE, Michel. 2006. Crime e Violência no Brasil Contemporâneo: estudos de sociologia do crime e da violência urbana. Rio de Janeiro: Lumen Juris Editora.

PREFEITURA DO MUNICÍPIO DE SÃO CARLOS. 2010. Plano de Atendimento à População em situação de rua do Centro de Referência Especializado de Assistência Social - Unidade de Atendimento a população em situação de rua. No prelo.

RANCIÈRE, Jacques. 2005. A partilha do sensível: estética e política. São Paulo: Ed. 34.

SANTOS, Wanderley. 1979. Cidadania e Justiça: a política social na ordem brasileira. Rio de Janeiro: Editora Campus Ltda.

SILVA, Vivian \& HERRERA, Ana. 2008. "Experiência de Gestão Municipal Atendimento a Pessoas em situação de rua". In Anais do Seminário Nacional sobre População em Situação de rua: Perspectivas e Políticas Públicas. São Carlos.

STRATHERN, Marilyn. 1991. “One Man and Many Men”. In M. Strathern \& M. Godelier (Orgs.). Big Men and Great Men: Personifications of Power in Melanesia. Cambridge: Cambridge University Press. 
2006. O gênero da dádiva. Campinas: Editora da UNICAMP.

TELLES, Vera. 2010. “Nas dobras do legal e do ilegal: ilegalismos e jogos de poder nas tramas da cidade". Dilemas: revista de estudos de conflitos e controle social 2(5-6).

\& HIRATA, Daniel. 2010. "Ilegalismos e jogos de poder em São Paulo”. Tempo Social revista de sociologia da USP 22(2).

WAGNER, Roy. 1991. "The Fractal Person". In M. Strathern \& M. Godelier (orgs.). Big Men and Great Men: Personifications of Power in Melanesia. Cambridge: Cambridge University Press. 


\section{A realidade do mundão: uma narrativa sobre a sociedade e a produção da desigualdade}

\section{RESUMO}

Neste artigo apresento uma narrativa feita por "moradores de rua" sobre a sociedade e a produção da desigualdade. Este estudo é resultado de uma pesquisa de campo realizada durante uma oficina que coordenei numa instituição de assistência social em São Carlos/SP. Trata-se de um discurso crítico sobre a produção da verdade acerca das relações sociais. A verdade, para eles, só pode ser extraída do conflito - o ponto central das relações. O texto segue em dois eixos analíticos: no primeiro, apresento o modo pelo qual os "moradores de rua" percebem as desigualdades e seus mecanismos reprodutores, e, no segundo, mostro como esses atores respondem criativamente à mecânica da exclusão, elaborando táticas de evasões cotidianas. Busco com isso contribuir, num plano analítico maior, para a reflexão sobre os conflitos sociais presentes na dinâmica sociopolítica urbana.

PALAVRAS-CHAVE: moradores de rua; conflitos sociais; relações de poder; antropologia política.

\section{The reality of the world outside: a narrative about society and the making of unequality}

\section{ABSTRACT}

This paper presents narratives made by "homeless people" about the society and the production of inequalities. This study is a result of fieldwork research conducted during a workshop that I have coordinated in a social welfare institution in Sao Carlos city, State of São Paulo. Their discourses deal with the possibilities of truth inside social relations. The truth, for them, can only result from conflict - the central point of the social relations. The text follows in two main lines of argument: the first presents how "homeless people" perceive inequalities and their reproductive mechanisms, and in the second, I show how these actors respond creatively to the mechanics of exclusion, developing tactics of avoidances. I intend to contribute for an analysis about social conflicts present in urban sociopolitical dynamics.

KEYWORDS: omeless; social conflicts; power relations; anthropology of politic.

Recebido em: 25/04/2012

Aprovado em: 3/10/2012 